Energy

Volume 168 Issue EN1

Vulnerability assessment of the European

natural gas supply

Olanrewaju, Chaudry, Qadrdan, Wu and

Jenkins

ice proceedings
Proceedings of the Institution of Civil Engineers

Energy 168 February 2015 Issue EN1

Pages 5-15 http://dx.doi.org/10.1680/ener.14.00020

Paper 1400020

Received 30/06/2014

Published online 26/02/2015

Accepted 13/01/2015

Keywords: energy/European Union/mathematical modelling

Published with permission by the ICE under the CC-BY license.

(http://creativecommons.org/licenses/by/4.0/) ice

$\overline{\text { Institution of Civil Engineers }}$

publishing

\title{
Vulnerability assessment of the European natural gas supply
}

Oluwabamise T. Olanrewaju MSc

Research Student, Institute of Energy, Cardiff University, Cardiff, UK Modassar Chaudry PhD

Research Associate, Institute of Energy, Cardiff University, Cardiff, UK

Meysam Qadrdan PhD

Research Associate, Control and Power Research Group, Imperial College

London, London, UK

\author{
Jianzhong Wu PhD \\ Senior Lecturer, Institute of Energy, Cardiff University, Cardiff, UK \\ Nick Jenkins PhD \\ Institute Leader, Institute of Energy, Cardiff University, Cardiff, UK
}

As indigenous natural gas reserves within the European Union (EU) decline, higher gas imports are expected in order to meet future EU gas demand. Natural gas will be transported across considerable distances from regions of gas reserves to European consumers. This raises security of gas supply concerns especially for EU countries that depend heavily on a single supply source or major transit route. A linear programming model of the European gas supplies was developed and used to investigate the impact of loss of the Ukraine transit capacity on gas supply from Russia to Europe. Two demand scenarios - that is a reference case and a high demand case in the winter of 2014/2015 were investigated. The results have shown that gas flows on interconnectors and from storage and liquefied natural gas import terminals compensated for the supply shortfall. Furthermore, to mitigate the effect of the supply shortage, the impact of increasing the capacities of selected pipelines within the EU was compared against increasing the maximum storage withdrawal rates in southeast Europe. Higher storage withdrawal rates achieved lower demand curtailment than the additional interconnector capacity in both scenarios.

Notation
$\mathrm{DZ}_{i, t}$
$\mathrm{DZC}_{i}$
$\mathrm{IC}_{s, t}$
$i, j$
$L_{l, t}$
$\mathrm{LC}_{l, t}$
$l$
$\mathbf{M}_{t}$
$\mathrm{PR}_{i, t}$
$\mathrm{PRC}_{i, t}$
$Q_{\mathrm{eq}}$
$Q_{i}$
$S_{s, t}^{\text {in }}$

unserved gas demand at node $i$ at time $t$

(million cubic metres $(\mathrm{mcm}) / \mathrm{d}$ )

cost of unserved demand at node $i$

$(€ / \mathrm{mcm})$

storage injection cost at facility $s$ at time $t$

$(€ / \mathrm{mcm})$

node indices

LNG volumes at a regasification terminal $l$

at time $t(\mathrm{mcm} / \mathrm{d})$

cost of LNG delivery at terminal $l$ at time $t$

$(€ / \mathrm{mcm})$

liquified natural gas regasification terminal index

node-flow incidence matrix

production/supply volume at node $i$ at time $t$ $(\mathrm{mcm} / \mathrm{d})$

cost of gas production/border supply cost

at node $i$ at time $t(€ / \mathrm{mcm})$

equivalent flow capacity in the single

equivalent pipeline

original individual pipeline capacity

gas volumes injected into a storage facility $s$ at time $t(\mathrm{mcm} / \mathrm{d})$

$S_{s, t}^{\text {out }}$
$s$
$T$
$\mathrm{TC}_{i, j, t}$
$\mathrm{TQ}_{i, j, t}$
$t$
$\mathrm{WC}_{s, t}$

\section{Introduction}

Natural gas is an important component of European energy supply and accounted for approximately $23 \%$ of primary energy consumption in 2011 (Eurogas, 2012). Natural gas is expected to play a significant role in achieving the climate and energy targets of the European Union (EU). In comparison to oil and coal, natural gas emits less carbon dioxide during combustion and can be used as a fuel for flexible electricity generation to support intermittent renewable energy resources.

Several scenarios have been developed to estimate future projections of natural gas demand in the EU (EC, 2013; Eurogas, 
2011). The anticipated demand outlook is driven primarily by the role of natural gas in electricity generation as shown in Figure 1 (EC, 2013). In the Eurogas scenario, natural gas demand for electricity is projected to increase by $29 \%$ from 2010 to 2030, whereas the EU energy trends reference scenario shows a demand decline of $16 \%$ over the same period.

The EU's gas supply comes from indigenous production, liquefied natural gas (LNG) and pipeline imports from Russia, Norway, Algeria and Libya. Historically, indigenous production, especially from the Netherlands and UK, accounted for the primary source of gas supply in the EU (ENSTOG, 2013a). As indigenous gas production declines, increasing reliance on imported gas supply is anticipated in order to meet future gas demand (Pöyry, 2010). EU gas imports are projected to reach $77 \%$ of total supply by 2020 (IEA, 2009). Consequently, gas supply to European consumers may involve long transport distance by way of transit countries from locations of abundant resources.

The European gas transmission network joins the natural gas transmission infrastructure of individual countries integrated into a single entity for delivery and transport of natural gas supplies across Europe. Major network infrastructure includes pipelines, compressor stations, LNG regasification terminals and gas storage facilities.

The existing pipeline network consists of cross-border pipelines between European countries and import pipelines linking

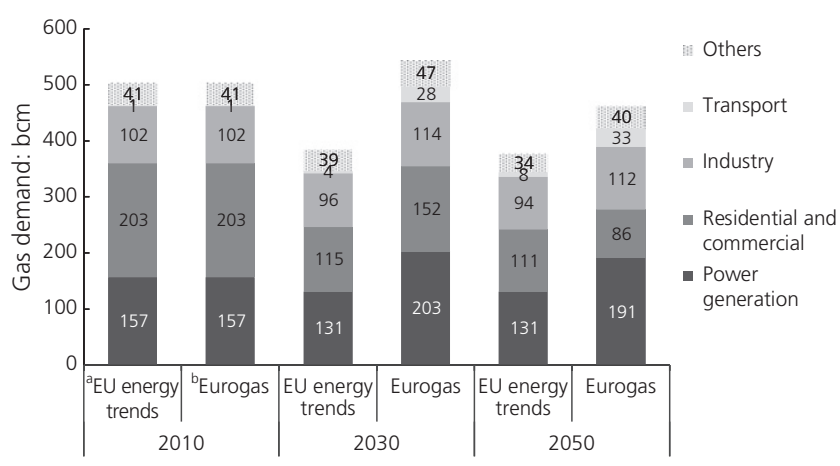

Figure 1. Comparison of EU gas demand projection by sector (billion cubic metres $(\mathrm{bcm})$ ). ${ }^{\mathrm{a}} \mathrm{EU}$ energy trends were produced by the EU Commission. The reference scenario portrays gas demand based on existing EU policies prior to July 2013; ${ }^{b}$ Eurogas scenario takes into consideration EU energy policies on energy efficiency and reduction in green house gas emissions. Reproduced by kind permission of Eurogas, Belgium and Publications office of the European Union, Luxembourg. Source: Eurogas (2011), EC (2013) major supply routes to Europe. Several pipeline projects have been proposed (e.g. Lithuania-Poland gas interconnector) to enhance market integration among EU member states (ENSTOG, 2013a).

Compressor stations are installed along long-distance highpressure pipelines to transport natural gas and maintain gas pressure in the network within acceptable limits. In Europe, $7000 \mathrm{MW}$ compression capacity has been planned alongside pipeline projects to improve network capacity and security of supply (ENSTOG, 2013a).

LNG regasification terminals are located mainly along the coasts of south and northwest Europe. LNG import promotes diversification of gas supply options for Europe (Noel et al., 2012). As a result, planned regasification terminal projects are expected to increase LNG import capacity from 198 billion cubic metres/year (bcm/y) in 2014 to $243 \mathrm{bcm} / \mathrm{y}$ by 2020 (GLE, 2014).

Natural gas storage offers buffer capacity to balance supply and demand during periods of peak demand or in the event of a gas supply disruption. Total gas storage capacity in Europe is presently approximately $99 \mathrm{bcm}$ (GSE, 2014). Several development projects have been planned across Europe and, if completed, will increase storage capacity by $20 \%$ in 2022 from the current levels (ENSTOG, 2013a).

The future demand outlook for natural gas is uncertain and domestic production is on the decline. However, a considerable number of projects have been planned to ensure that the European gas network can adequately meet a wide range of demand and supply situations in Europe. This study examined the impact of a supply shock on the existing network.

\subsection{Challenges of the European natural gas network}

The primary role of the European gas network is to ensure secure supply of natural gas to Europe. However, certain instances of supply disruptions have highlighted the limited capability of the gas network to respond adequately to supply shocks.

An example of a supply disruption was the shut-off of gas flow from Russia through Ukraine to Europe in January 2009 (EC, 2009). Russian gas supplies approximately $25 \%$ of Europe's gas demand (Dieckhoner 2012). Previously, 80\% of these gas volumes reached Europe through transit pipelines in Ukraine (Dieckhoener, 2012). However, gas flow through Ukraine has reduced to approximately $50 \%$ of its previous value since the Nord stream pipeline began operation in 2011 (EIA, 2014). The Nord Stream pipeline directly transports gas from Russia to Germany through the Baltic Sea (see Table 1). 


\begin{tabular}{lllll} 
Name & Source & $\begin{array}{l}\text { Annual } \\
\text { capacity: bcm }\end{array}$ & Route & Status \\
\hline Brotherhood/Soyuz & Russia & 134 & Russia/Ukraine-Slovakia/Hungary/Poland/Romania & Existing \\
Yamal-Europe & Russia & 34 & Russia/Belarus-Poland/Lithuania & Existing \\
Nord Stream I/II & Russia & 55 & Russia-Germany & Existing \\
South Stream & Russia & 63 & Russia-Bulgaria-Austria/ltaly & Planned \\
Trans-Anatolian natural gas pipeline & Caspian & $10-16$ & Azerbaijan/Georgia-Turkey & Planned
\end{tabular}

Table 1. Key pipeline import capacities to Europe from Russia and the Caspian region (National Grid, 2012)

As a consequence of the supply disruption of January 2009, some countries in eastern and southeastern Europe were unable to maintain gas supplies to all their demand sectors (EC, 2009). Some of the challenges that this event highlighted include dependency of some member states on a single source of supply/route, lack of bi-directional flow on some interconnectors between countries and limited gas storage capacities (Stern, 2009).

Mitigation measures such as diversification of supply sources and routes are being proposed to improve resilience of the European gas network. Noel et al. (2012) presented measures to improve security of gas supply in Europe based on regional co-operation. As a measure to diversify gas supply sources, major gas reserves with potential for delivery to Europe are being developed in the Caspian region. The Shah gas field development in Azerbaijan is expected to supply 10-16 bcm annually by 2020 through the trans-Anatolian natural gas pipeline through Turkey into southern Europe as shown in Table 1 (BP, 2013). In addition, physical integration of the national gas networks through investment in reverse flow capacities and new cross-border pipelines will contribute to gas supply security.

\subsection{Modelling of European gas supply}

Studies on the operation of the European gas system have been reported in the literature.

These studies involved the assessment of infrastructure capacities and gas supply availability to meet the different demand conditions adequately.

The complementarity models of the European gas market are reported by Lise et al. (2008), Holz et al. (2008) and Egging et al. (2008). These models focus on the impact of the behaviour of market agents and competition on the operation of the European gas market.

Using a Monte Carlo probabilistic approach, Szikszai and Monforti (2011) developed a gas network model to assess the effect of a potential supply crisis on the gas flows in the
European gas system. An optimal allocation of gas supply based on a set of rules was proposed to minimise the supply shortfall.

Carvalho et al. (2014) developed a novel approach to manage gas network congestion in the event of an emergency crisis situation situation. This method built on the internet congestion control approach, considered a fair distribution strategy for access to network capacity during a gas supply crisis.

The transport infrastructure for gas with enhanced resolution (Tiger) model (Lochner and Bothe, 2007) is a detailed representation of the European gas supply system based on the linear optimisation approach.

Dieckhoener (2012) used the Tiger model to investigate the possible contribution of the proposed gas import pipeline projects to security of supply in Europe. On the basis of this study, insufficient interconnector capacities within South East Europe led to unmet demand in the region.

In this paper, a simplified European gas supply model was developed to model the gas flows using the linear optimisation approach. This study examined the potential impact of the loss of Ukraine's transit capacity on gas supply to Europe in winter 2014.

\section{Simplified European gas network model}

\subsection{Methodology and assumptions}

The following assumptions were made to obtain the simplified network

only existing (i.e. in operation) natural gas infrastructure that is pipelines, storage and LNG facilities in 2013 were considered

- units of gas capacity are presented as million cubic metres $(\mathrm{mcm})$ and $\mathrm{bcm}$ at standard conditions of temperature $15^{\circ} \mathrm{C}$ and pressure $101 \cdot 325 \mathrm{kPa}$. Conversion factors are $1 \mathrm{~m}^{3}$ of natural gas $=39.6 \mathrm{MJ}$ gross calorific value $(\mathrm{GCV})=10 \cdot 8 \mathrm{kWh}$. 
Vulnerability assessment of the European

natural gas supply

Olanrewaju, Chaudry, Qadrdan, Wu and

Jenkins

\subsubsection{Network components}

The simplified European gas network model consists of 40 nodes and 63 interconnectors between countries, as shown in Figure 2. The nodes represent individual countries and the aggregated capacities of their major gas facilities connected to the European network.

For European countries, nodal parameters include total gas demand, total production capacity, total storage capacity and total LNG capacity if applicable. Nodal parameters for nonEuropean source countries are limited to their total export capacities to Europe. In this study, Europe includes EU28, Bosnia and Herzegovina, Macedonia, Serbia, Switzerland and Turkey.
Gas pipelines are characterised by different pipe lengths and flow capacities. On the basis of network topology, one or more pipelines could link any two countries. Multiple cross-border pipelines between countries are summed up to represent a single pipeline capacity using Equation 1

1. $Q_{\mathrm{eq}}=\sum_{i=1}^{n} Q_{i}$

where $Q_{\mathrm{eq}}$ is the equivalent flow capacity in the single equivalent pipeline and $Q_{i}$ are original individual pipeline capacities.

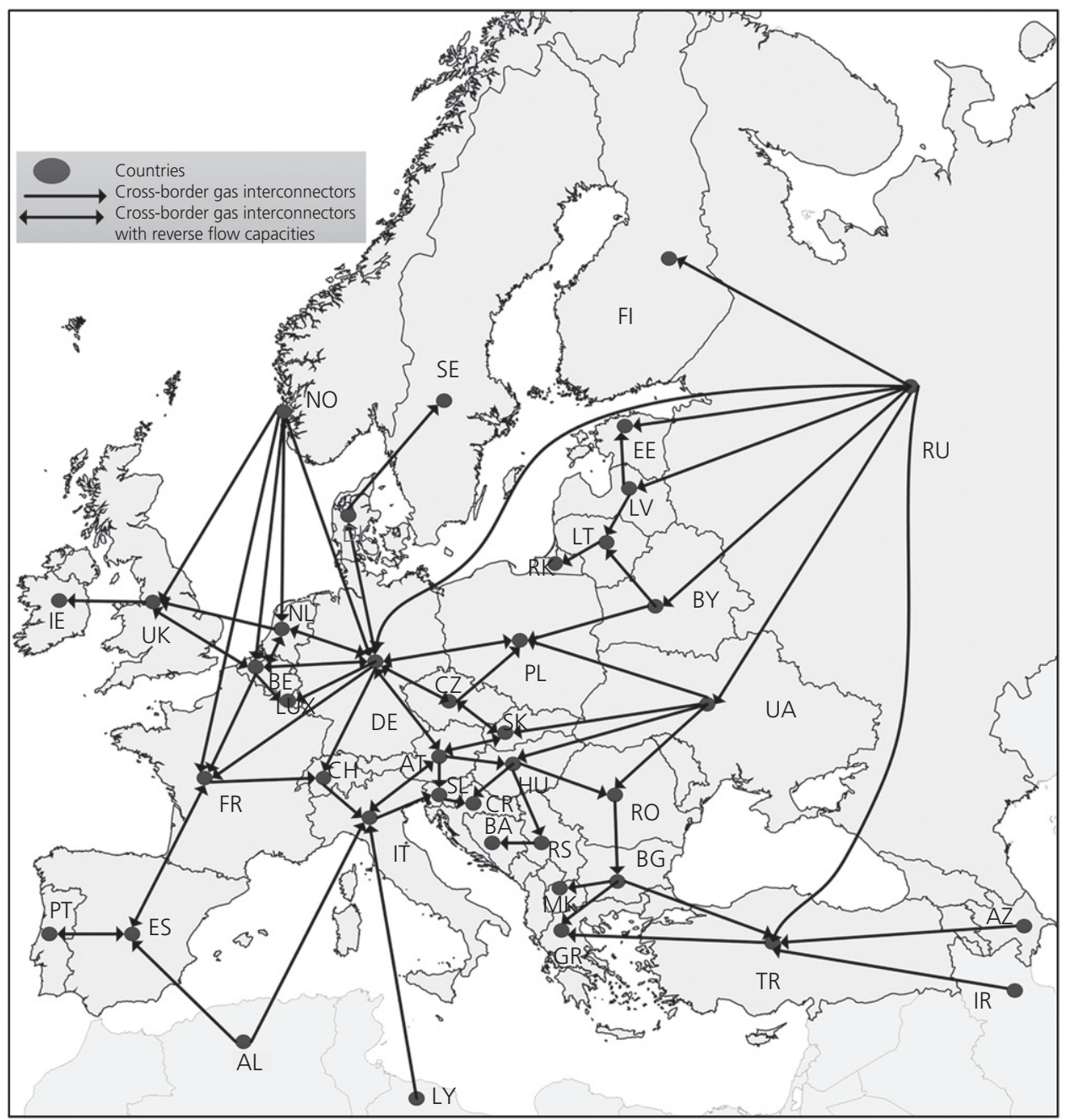

Figure 2. Simplified European gas network diagram (see Appendix $A$ in the online supplementary data accompanying this paper for a list of country codes) (gas interconnector from RU to TR represents existing capacity on Blue Stream pipeline, whereas gas interconnector from AZ to TR represents existing capacity on South Caucasus pipeline). Reproduced by the kind permission of worldatlas, Canada 


\subsection{Description of the model}

The simplified European gas network model is formulated using the commercial optimisation tool FICO Xpress optimisation suite (FICO, 2014). The model is developed as a linear programming optimisation model to examine optimal operation of the gas network. The linear optimisation approach assumes efficient dispatch of natural gas along all supply routes across Europe, neglecting the inefficiencies due to market operation or contractual arrangements. Furthermore, the total system operation is considered from the perspective of a single system operator as opposed to separate regional grid operators in Europe. This model is used to identify supplydemand gaps and mitigation measures.

Figure 3 shows the flow diagram of the simplified European gas network model. The model comprises input parameters, objective function, constraints and variables needed to provide the output data that describe the network operation. Input parameters include demand, supply capacities separated into indigenous productions and gas imports. Cost parameters relevant to specific gas infrastructure are also given in the model. The costs include supply/production, transportation and, where relevant, LNG import cost and storage operation costs. A daily time step is considered over the winter duration.

\subsection{Modelling}

\subsubsection{The objective function}

The objective function is to minimise the total cost of natural gas supply required to meet the demand adequately

Minimise total operational cost $(€)=$

2. $\sum_{t}\left(\begin{array}{c}\sum_{i}\left[\mathrm{PRC}_{i, t} \mathrm{PR}_{i, t}\right]+\sum_{i, j}\left[\mathrm{TC}_{i, j, t} \mathrm{TQ}_{i, j, t}\right] \\ +\sum_{s}\left[\mathrm{IC}_{s, t} S_{s, t}^{\text {in }}-\mathrm{WC}_{s, t} S_{s, t}^{\text {out }}\right] \\ +\sum_{l}\left[\mathrm{LC}_{l, t} L_{l, t}\right]+\sum_{i}\left[\mathrm{DZC}_{i} \mathrm{DZ}_{i, t}\right]\end{array}\right)$

MODEL

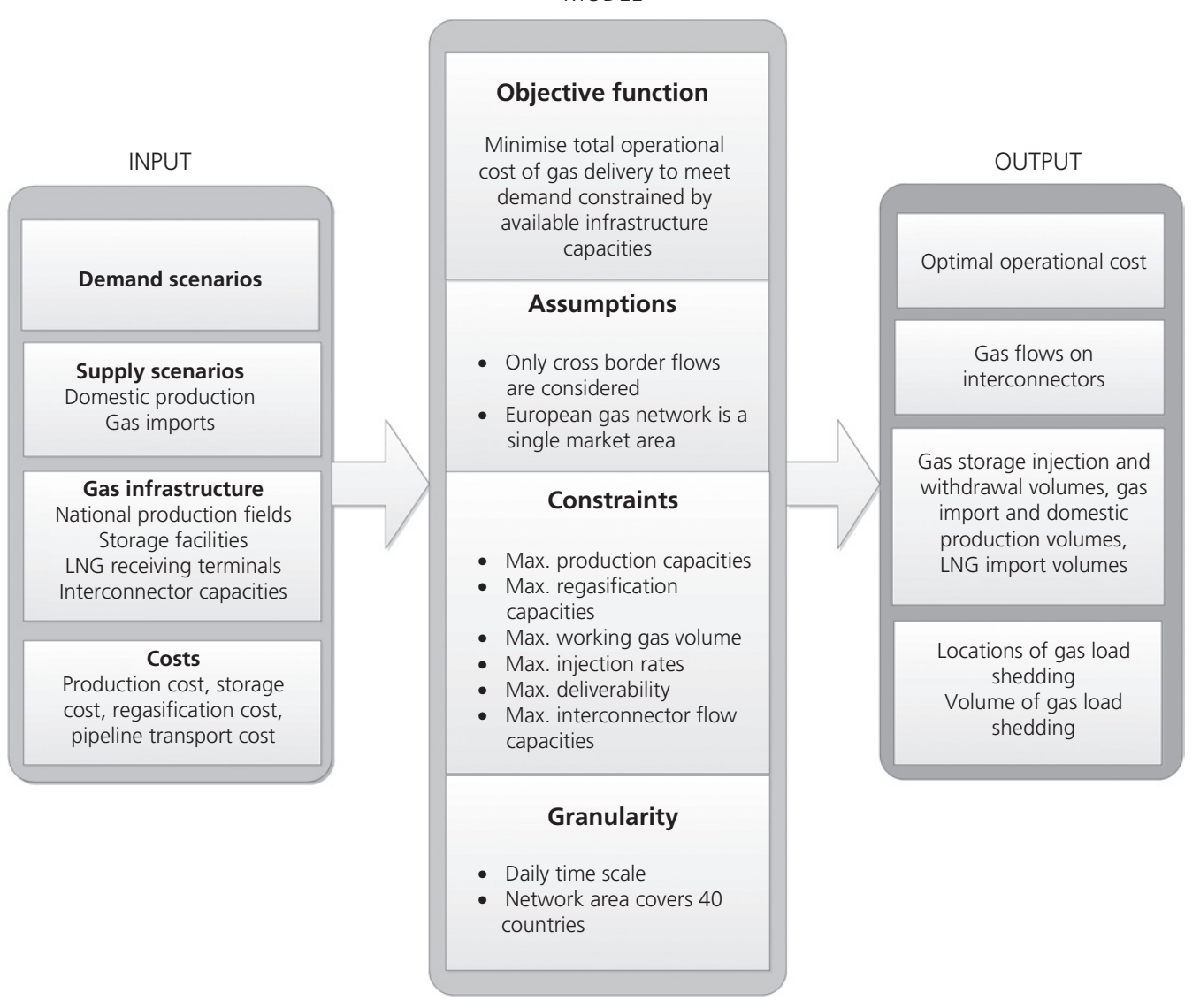

Figure 3. Flow diagram of the simplified European gas network model 
The total supply cost presented in Equation 2 accounts for costs of gas supplies (from domestic production and gas imports) + gas transport + storage operation + LNG terminal operation + unmet gas demand. Technical limitations and characteristics of production, transport storage and LNG facilities are the constraints of the optimisation (see Appendix $\mathrm{C}$ in the online supplementary data accompanying this paper).

\subsubsection{Nodal balance}

At each node in the network, gas demand must be balanced by gas supply (Equation 3). For each time step, gas inflow at each node (gas supply, storage withdrawal) is balanced by gas outflows (gas demand and storage injection)

$$
\text { 3. } D_{i, t}-\mathrm{DZ}_{i, t}=\sum_{i} \mathbf{M}_{t} \mathrm{TQ}_{i, j, t}+\mathrm{PR}_{i, t}+L_{i, t}+S_{s, t}^{\text {out }}-S_{s, t}^{\text {in }}
$$

\subsection{Model validation}

To validate the model, cross-border flows obtained from the model for 2010 were compared with the trade flow aggregates obtained from publicly available data from DECC (2012). Average LNG supply cost for EU countries and average gas pipeline supply cost to the EU were used for the supply cost from producer countries. Supply costs for both LNG and pipeline supplies were derived from IEA World Energy Outlook (IEA, 2011) and the quarterly report on the European gas market (DG Energy, 2010). Results of the comparison between simulations and actual data are presented in Table 2.

The results of the simulation matched the real data except for a few cases. Since long-term contracts between producers and destination countries were not taken into account, gas supplies from the least-cost sources along cost-effective routes displaced more expensive gas imports. For instance, Norwegian gas supply to the UK displaced some volumes of higher-cost gas to the UK from the Netherlands.

\section{Description of case studies}

\subsection{Demand assumptions}

The case studies are based on the projected gas demand for winter 2014 using the existing European natural gas network. Two demand cases are defined. Heating demand accounts for $35 \%$ of total gas demand in both demand cases based on historical data of heating gas consumption in Europe (IEA, 2012).

\subsubsection{Reference case}

The reference case represents a low winter gas demand for 2014. Daily demand was derived from average daily consumption based on historical monthly demand consumption for all

\begin{tabular}{|c|c|c|c|}
\hline From country & To country & Actual: bcm & Simulated: bcm \\
\hline LNG import & Belgium & $6 \cdot 4$ & $4 \cdot 5$ \\
\hline Netherland & Belgium & $19 \cdot 7$ & $21 \cdot 3$ \\
\hline Norway & Belgium & $7 \cdot 0$ & $14 \cdot 6$ \\
\hline UK & Belgium & $8 \cdot 8$ & $3 \cdot 5$ \\
\hline Czech Republic & Germany & $17 \cdot 0$ & $21 \cdot 8$ \\
\hline Norway & Germany & $32 \cdot 2$ & $27 \cdot 0$ \\
\hline Poland & Germany & $33 \cdot 0$ & $22 \cdot 0$ \\
\hline Belgium & France & $13 \cdot 5$ & $16 \cdot 0$ \\
\hline LNG import & France & $14 \cdot 0$ & $10 \cdot 0$ \\
\hline Norway & France & $19 \cdot 1$ & $18 \cdot 5$ \\
\hline Austria & Italy & $18 \cdot 5$ & $20 \cdot 0$ \\
\hline LNG import & Italy & $12 \cdot 6$ & $11 \cdot 0$ \\
\hline Norway & Netherland & $12 \cdot 9$ & $9 \cdot 2$ \\
\hline Algeria & Spain & $9 \cdot 1$ & $9 \cdot 0$ \\
\hline LNG import & Spain & $27 \cdot 8$ & $28 \cdot 7$ \\
\hline Netherland & UK & $8 \cdot 2$ & $4 \cdot 5$ \\
\hline Norway & UK & $25 \cdot 0$ & $30 \cdot 0$ \\
\hline LNG & UK & $18 \cdot 6$ & $14 \cdot 1$ \\
\hline
\end{tabular}

Table 2. Comparison of gas flows and LNG import simulation result to actual data for 2010 (see Appendix B in the online supplementary data accompanying this paper for supply costs data)

European countries (Eurostat, 2014a). To obtain the average daily consumption, the monthly gas consumption was divided by the number of days in each month. The demand data are summarised in Table 3.

\begin{tabular}{lccc}
\hline Country & $\begin{array}{c}\text { Reference } \\
\text { case: } \\
\mathrm{mcm} / \mathrm{d}\end{array}$ & $\begin{array}{c}\text { High- } \\
\text { demand } \\
\text { case: } \mathrm{mcm} / \mathrm{d}\end{array}$ & $\begin{array}{c}\text { Peak day } \\
\text { demand: } \\
\mathrm{mcm} / \mathrm{d}^{\mathrm{a}}\end{array}$ \\
\hline Germany & $219 \cdot 18$ & 263.016 & 489 \\
UK & $220 \cdot 70$ & 264.84 & 487 \\
France & $131 \cdot 30$ & 157.56 & 419 \\
Spain & 109.90 & 131.88 & 205 \\
Italy & 229.66 & 275.592 & 486 \\
Other European countries & 468.37 & 562.044 & 913 \\
\hline
\end{tabular}

${ }^{\mathrm{a}}$ One in 20 years peak day demand obtained from the 10-year network plan is applied to both reference and high demand cases. It is also assumed to occur concurrently in all the European countries. Heating demand refers to gas demand of the domestic and commercial sectors (ENSTOG, 2013b; Eurostat, 2014a)

Table 3. European winter demand assumptions for 2014 
Energy

Volume 168 Issue EN1
Vulnerability assessment of the European

natural gas supply

Olanrewaju, Chaudry, Qadrdan, Wu and

Jenkins

\begin{tabular}{lc} 
Supply source & Maximum supply: $\mathrm{mcm} / \mathrm{d}$ \\
\hline Russia & $500 \cdot 00$ \\
Norway & $330 \cdot 00$ \\
Algeria & $111 \cdot 40$ \\
Libya & $30 \cdot 10$ \\
Aggregated national production $^{\mathrm{a}}$ & $724 \cdot 68$ \\
Total LNG import $^{\mathrm{b}}$ & $355 \cdot 00$
\end{tabular}

${ }^{a}$ Aggregated natural production includes production supply volumes from all European countries that have indigenous natural gas reserves

${ }^{\text {b}}$ Total LNG import refers to the maximum potential LNG import supplies to Europe

Table 4. European winter gas supply for 2014 - major gas supply sources

\subsubsection{High-demand case}

The high-demand case assumes $20 \%$ increase in the gas demand of the reference case (see Table 3 ).

\subsection{Gas supply and capacity assumptions}

Supply data obtained from the 10-year network development plan (ENSTOG, 2013b) are shown in Table 4. On the basis of historical winter supply, the average gas supply from pipeline import sources and LNG import was increased by $10 \%$ to obtain the maximum available supply (Eurostat, 2014b).

The maximum interconnector capacities, total daily $\mathrm{LNG}$ regasification capacity and total storage capacity obtained for several sources of particular importance are shown in Table 5 (see Appendix B in the online supplementary data accompanying this paper for detailed data).

\subsection{Simulation assumptions}

The simulation has a daily time step and was run over 182 days from October 2014 to March 2015. The loss of all transmission capacities to Europe routed through Ukraine was examined for a period of 30 days from mid-January to mid-February.

\subsection{Mitigation measures}

Two different mitigation measures are applied to each of the demand cases.

\subsubsection{Additional interconnector capacities in Europe}

Transmission capacities of selected interconnectors are increased to allow greater gas flow from west to east Europe. This increase in capacity could be achieved by investment in

\begin{tabular}{lr} 
Interconnector/facility & $\begin{array}{r}\text { Maximum capacity: } \\
\mathrm{mcm} / \mathrm{d}\end{array}$ \\
\hline Ukraine-Hungary & $67 \cdot 80$ \\
Ukraine-Slovakia & $218 \cdot 00$ \\
Ukraine-Poland & $15 \cdot 66$ \\
Ukraine-Romania $^{\text {Combined LNG regasification capacity }}$ & $80 \cdot 30$ \\
Combined maximum storage $^{\text {withdrawal rate }}{ }^{\text {b }}$ & $562 \cdot 97$ \\
\end{tabular}

${ }^{a}$ Combined LNG regasification capacity includes the capacities of all LNG facilities in Europe

${ }^{b}$ Combined maximum storage withdrawal rate aggregates the maximum storage withdrawal rates of all existing storage facilities in Europe (ENSTOG, 2013c; GLE, 2014; GSE, 2014)

Table 5. Maximum flow capacities on selected major transit interconnectors and gas facilities

additional compression stations or upgrading existing stations with additional compressor units. Flow capacity on the Hungary-Romania interconnector is increased from 4.09 to 8.18 million cubic metres per day $(\mathrm{mcm} / \mathrm{d})$, whereas flow capacity on the Hungary-Serbia interconnector is increased from 11.2 to $22.4 \mathrm{mcm} / \mathrm{d}$. Reverse flow capacity of $9.6 \mathrm{mcm} / \mathrm{d}$ is also allowed on the Greece-Bulgaria interconnector. In addition, the capacity of the Russia-Germany interconnector is extended from 85 to $150 \mathrm{mcm} / \mathrm{d}$. Nord Stream consists of two parallel pipelines having a total capacity of $150 \mathrm{mcm} / \mathrm{d}$.

\subsubsection{Higher storage withdrawal rates in South East Europe}

The volume of gas that can be extracted from storage facilities depends on the maximum storage withdrawal rate and the working gas volume. A 50\% increase in maximum withdrawal rate is applied to selected countries: Serbia, Romania and Bulgaria.

\section{Simulation results}

\subsection{Simulation results of case studies without the loss of Ukraine transit capacity}

The results are expressed as average winter day gas volume (calculated as the average gas volume over the 30 days duration of the supply disruption) except where otherwise stated.

\subsubsection{Domestic production and import gas volume to Europe}

Figure 4 shows the comparison of gas supply volumes from domestic production and import sources without the loss of 


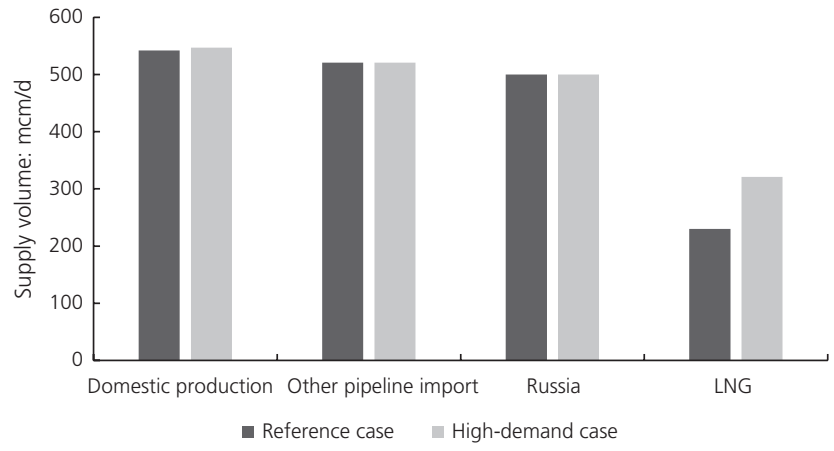

Figure 4. Domestic production and gas import supplies to Europe - no loss of Ukraine transit capacity

the Ukraine transit capacity. Domestic gas production accounted for $30 \%$ of total supplies in the reference case and $29 \%$ of total supplies in the high-demand case. The average gas supplied from Russia was $500 \mathrm{mcm} / \mathrm{d}$, accounting for $28 \%$ of total supplies in the reference case and $26.5 \%$ of total supplies in the high-demand case. LNG volumes increased from $230 \mathrm{mcm} / \mathrm{d}$ in the reference to $321 \mathrm{mcm} / \mathrm{d}$ in the highdemand case.

\subsubsection{Storage withdrawal}

Gas volumes withdrawn from storage facilities are presented in Figure 5. Gas storage facilities in Other Europe showed the largest gas withdrawals of $132 \mathrm{mcm} / \mathrm{d}$ in the reference case and $224 \mathrm{mcm} / \mathrm{d}$ in the high-demand case. German storage withdrawals increased from $95.18 \mathrm{mcm} / \mathrm{d}$ in the reference case to

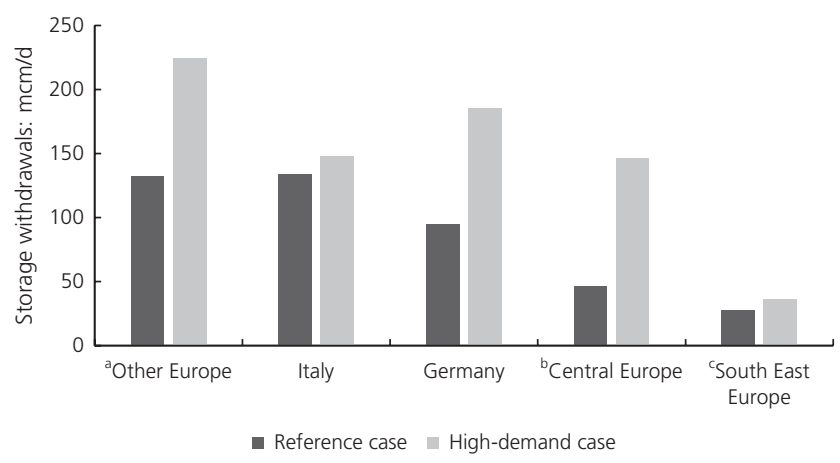

Figure 5. Gas withdrawn from European storage facilities - no loss of Ukraine transit capacity. ${ }^{\mathrm{a}}$ Other Europe comprises storage facilities in Europe an countries excluding southeast Europe, Germany and Italy; ${ }^{b}$ Central Europe includes Austria, Czech Republic, Poland, Hungary and Slovakia; 'South East Europe includes Bulgaria, Croatia, Romania, Serbia and Turkey
$185.10 \mathrm{mcm} / \mathrm{d}$ in the high-demand case. Central Europe storage withdrawals increased by $214 \%$ in the high-demand case compared with reference case, whereas gas withdrawals in South East Europe increased by $28 \%$ in the high-demand case against the reference case.

\subsection{Impact of the loss of Ukraine transit capacity}

The loss of the Ukraine transit capacity was then applied for a 30 day period. The results of the simulation with the supply disruption are presented.

\subsubsection{Domestic production and import gas volume to Europe}

Domestic production volume increased by $7.78 \mathrm{mcm} / \mathrm{d}$ in the reference case and $12.09 \mathrm{mcm} / \mathrm{d}$ in the high-demand case (see Figures 4 and 6) with the loss of the Ukraine transit capacity.

There was a $52 \%$ decline in gas volumes supplied to Europe from Russia in both demand cases when compared with the condition in which no Ukraine transit loss occurred.

LNG supplies increased by $5.4 \%$ in the reference case and $7 \cdot 7 \%$ in the high-demand case to replace some of the supply shortfall.

\subsubsection{Withdrawal from storage}

Figure 7 shows additional withdrawals from gas storage of $52.63 \mathrm{mcm} / \mathrm{d}$ in Other Europe, $61.67 \mathrm{mcm} / \mathrm{d}$ in Italy and $138.21 \mathrm{mcm} / \mathrm{d}$ in Central Europe for the reference case. The gas volumes withdrawn from German storages increased from $108.52 \mathrm{mcm} / \mathrm{d}$ in the reference case to $233.04 \mathrm{mcm} / \mathrm{d}$ in the high-demand case. Gas withdrawals of $54 \mathrm{mcm} / \mathrm{d}$ in South East Europe remain unchanged in both the reference case and high-demand case. This reflects the limited capacity of storage facilities within that region.

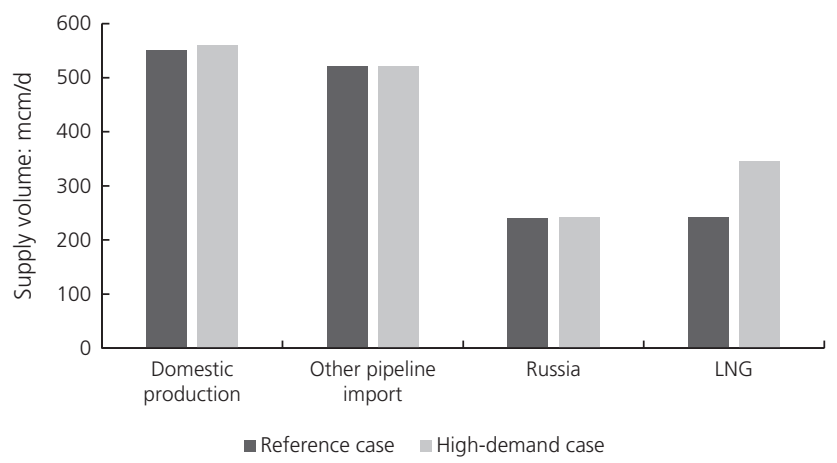

Figure 6. Domestic production and gas import supplies to Europe - loss of Ukraine transit capacity 
Energy

Volume 168 Issue EN1
Vulnerability assessment of the European

natural gas supply

Olanrewaju, Chaudry, Qadrdan, Wu and

Jenkins

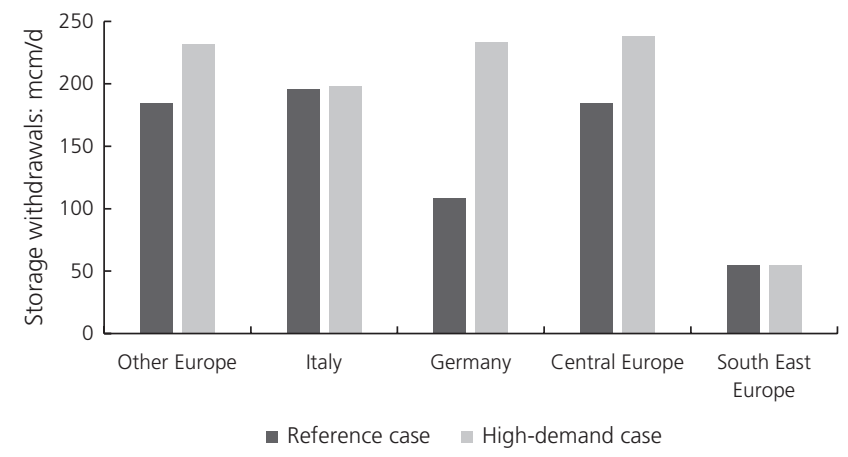

Figure 7. Gas withdrawn from storage - loss of Ukraine transit capacity

\subsubsection{Unmet gas demand}

The average day unmet gas demands in countries affected by the supply disruption are presented in Table 6. Unmet demand occurred in southeastern European countries that mainly rely on the Ukraine transit route and have limited access to alternative supply sources or transport routes. In Bosnia, Bulgaria and Macedonia between $4 \%$ and $54 \%$ of gas demand was unmet in the reference case. In the high-demand case, Romania failed to meet $7 \cdot 12 \%$ of gas demand and Greece shed $4 \cdot 22 \%$ of average daily demand in comparison with no unmet demand in the reference case. Access to LNG supplies minimised the effect of the supply shortfall in Greece while Romania utilised stored gas to compensate some of the missing gas volumes.

\begin{tabular}{|c|c|c|c|c|}
\hline \multirow[b]{2}{*}{ Country } & \multicolumn{2}{|c|}{ Reference case } & \multicolumn{2}{|c|}{ High-demand case } \\
\hline & $\mathrm{mcm} / \mathrm{d}$ & $\begin{array}{c}\text { \% Of average } \\
\text { day demand } \\
\text { unmet }^{a}\end{array}$ & $\mathrm{mcm} / \mathrm{d}$ & $\begin{array}{c}\text { \% Of average } \\
\text { day demand } \\
\text { unmet }^{a}\end{array}$ \\
\hline Bosnia & 0.09 & 3.94 & 2.04 & $78 \cdot 76^{\mathrm{b}}$ \\
\hline Bulgaria & $2 \cdot 16$ & $16 \cdot 40$ & $9 \cdot 60$ & $60 \cdot 76$ \\
\hline Macedonia & 0.56 & $54 \cdot 17$ & $1 \cdot 3$ & $97 \cdot 43^{b}$ \\
\hline Romania & 0.00 & 0.00 & $4 \cdot 12$ & $7 \cdot 21$ \\
\hline Greece & 0.00 & 0.00 & 0.76 & $4 \cdot 22$ \\
\hline
\end{tabular}

average day demand is the average daily demand over the 30 days duration of supply disruption

${ }^{b}$ Heating demand is not interrupted over the duration of supply disruption. In 2012, heating demand accounted for $19 \%$ of total gas consumption in Bosnia and $2 \%$ of total gas consumption in Macedonia (Honore, 2014)

Table 6. Average day unmet demand - loss of Ukraine transit capacity

\begin{tabular}{lccc} 
Case study & $\begin{array}{c}\text { Base case: } \\
\mathrm{mcm} / \mathrm{d}^{\mathrm{a}}\end{array}$ & $\begin{array}{c}\text { Higher storage } \\
\text { withdrawal } \\
\text { rates: } \mathrm{mcm} / \mathrm{d}\end{array}$ & $\begin{array}{c}\text { Additional } \\
\text { interconnector } \\
\text { capacities: } \\
\mathrm{mcm} / \mathrm{d}\end{array}$ \\
\hline Reference case & $24 \cdot 3$ & $25 \cdot 8$ & $36 \cdot 4$ \\
High-demand case & 23.5 & 26.9 & 38.0 \\
\hline
\end{tabular}

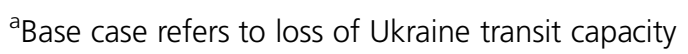

Table 7. Gas flow on interconnectors in South East Europe

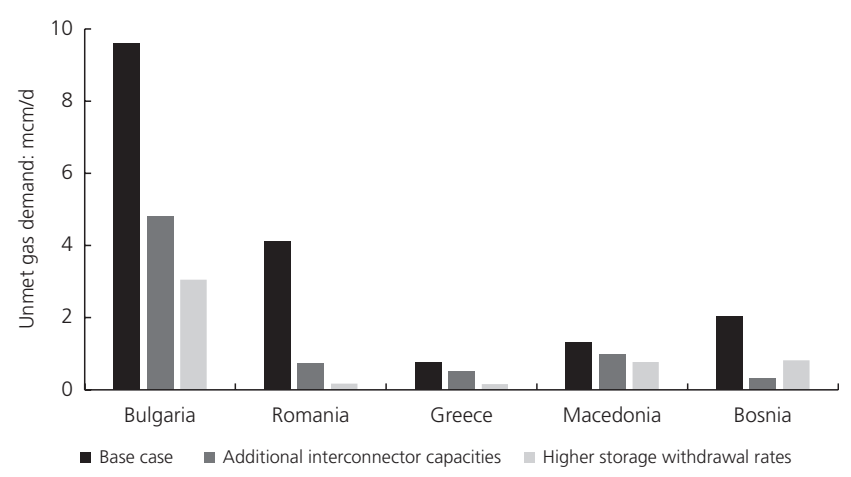

Figure 8. Comparison of unmet gas demand in the high-demand case after applying the different mitigating measures

\subsection{Simulation results of the mitigation strategies}

The increase in flow capacities on selected interconnectors in South East Europe (see Section 3.4.1) resulted in an additional gas flow of $12.1 \mathrm{mcm} / \mathrm{d}$ in the reference case and $14.5 \mathrm{mcm} / \mathrm{d}$ in the high-demand case compared with the base case (Table 7). The base case refers to the loss of Ukraine transit capacity.

Additional interconnector capacity led to unmet demand of $0.3 \mathrm{mcm} / \mathrm{d}$ in Bosnia, $0.8 \mathrm{mcm} / \mathrm{d}$ in Romania and $3 \mathrm{mcm} / \mathrm{d}$ in Bulgaria (Figure 8). A higher storage withdrawal rate resulted in less than $1 \%$ unmet demand in Greece $(0.16 \mathrm{mcm} /$ d) and Romania $(0.17 \mathrm{mcm} / \mathrm{d})$ and $6 \%(0.77 \mathrm{mcm} / \mathrm{d})$ unmet demand in Macedonia.

\section{Conclusions}

A European gas network model was described. The model represented all gas interconnectors including routes to major import sources, LNG terminals and storage facilities in Europe. The model was used to investigate the impact of the loss of gas transit capacity through Ukraine on European gas supply for winter 2014/2015. 
In the event of a 30 days loss of Ukraine transit capacity, the simulation results showed that a combination of LNG supplies and available stored gas will be used to compensate for the supply shortfall. The natural gas supply adequately matched demand in western and Central Europe for both demand cases due to diversified supply sources and access to sufficient volumes of stored gas.

On the other hand, considerable unmet demand was evident in Macedonia, Bosnia and Bulgaria in South East Europe showing that this region was reliant on the Ukraine transit route and had limited alternative supply routes. The winter supply outlook 2014/2015 recently conducted by the European Network of Transmission System Operators for Gas confirms that the loss of Ukraine transit capacity during peak demand situations will significantly impact South East Europe (ENSTOG, 2014).

Additional capacities on selected gas interconnectors were shown to increase gas volumes to South East Europe. Full utilisation of spare capacity on the Nord Stream pipeline allowed rerouting of Russian gas supplies through Germany to Central Europe. In addition, storage withdrawals in Germany and Central Europe could be diverted to locations of supply shortage by way of reverse flow capacity on gas interconnectors within Central Europe and South East Europe.

Finally, higher storage capacity in South East Europe reduced instances of demand shortage. However, diversification of supply sources such as gas supplies from the Caspian region or more LNG receiving terminals will become increasingly important to ensure security of supply in this region.

\section{Acknowledgements}

The authors acknowledge RCUK's Energy Programme for the financial support of this work through the Top \& Tail Transformation programme grant, EP/I031707/1 (http://www. topandtail.org.uk/) and the HubNet Consortium grant EP/ I013636/1 (www.hubnet.org.uk).

\section{REFERENCES}

BP (British Petroleum) (2013) Shah Deniz Stage 2. BP Exploration (Shah Deniz) Limited, Baku, Azerbaijan. See http://www.bp.com/content/dam/bp/pdf/Press/shah_deniz_ 2_brochure_english.pdf (accessed 05/08/2013).

Carvalho R, Buzna L, Bono F, Masera M, Arrowsmith DK et al. (2014) Resilience of natural gas networks during conflicts, crises and disruptions. PLoS ONE 9(3): e90265.

DECC (Department of Energy \& Climate Change) (2012)

Digest of United Kingdom Energy Statistics 2012. DECC, London, UK.
DG Energy (2010) Quarterly Report on European Gas Market. Directorate General Energy, European Commission, Brussels, Belgium.

Dieckhoner C (2012) Simulating security of supply effects of the Nabucco and South stream projects for the European natural gas market. The Energy Journal 33(3): 153-179.

EC (European Commission) (2009) The January 2009 Gas Supply Disruption to the EU: an Assessment. EC, Brussels, Belgium. See http://ec.europa.eu/energy/strategies/2009/doc/ sec_2009_0977.pdf (accessed 24/05/2013).

EC (2013) EU Energy Trends, Transport and GHG Emissions Trends to 2050. European Commission, Luxembourg. See http://ec.europa.eu/energy/observatory/trends_2030/doc/ trends_to_2050_update_2013.pdf (accessed 02/11/2014).

Egging R, Gabriel SA, Holz F and Zhuang J (2008) A complementarity model for the European natural gas market. Energy Policy 36(7): 2385-2414.

EIA (U.S. Energy Information Administration) (2014) 16\% of Natural Gas Consumed in Europe Flows Through Ukraine. EIA, Washington, DC, USA. See http://www.eia.gov/ todayinenergy/detail.cfm?id=15411 accessed 02/06/2014).

ENSTOG (European Network of Transmission System Operators for Gas) (2013a) Ten-year Network Development Plan (2013-2022). ENSTOG, Brussels, Belgium. See http://www.entsog.eu/publications/tyndp/ 2013\#ENTSO-

TEN-YEAR-NETWORK-DEVELOPMENTPLAN-2013-2022 (accessed 01/12/2013).

ENSTOG (2013b) Ten Year Network Development Plan 2013-2022- Annex C: Supply \& Demand Corrigendum. ENSTOG, Brussels, Belgium. See http://www.entsog.eu/ publications/tyndp\#ENTSO-TEN-YEARNETWORKDEVELOPMENT-PLAN-2013-2022 (accessed 02/04/2014).

ENSTOG (2013c) The European Natural Gas Network(Capacities at Cross-Border Points on the Primary Market). ENSTOG, Brussels, Belgium. See http://www. entsog.eu/maps/transmission- capacity-map/2013 (accessed 03/02/2014).

ENSTOG (2014) Winter Supply Outlook 2014/15. ENSTOG, Brussels, Belgium. See http://www.entsog.eu/public/ uploads/files/publications/Outlooks \& Reviews/2014/ SO0008-141103_WinterSupplyOutlook2014-15_ Review2013-14.pdf (accessed 10/11/2014).

Eurogas (2011) Eurogas Roadmap 2050. Eurogas, Brussels, Belgium. See http://www.eurogas.org/uploads/media/ Eurogas_Roadmap_2050_-_summary_13.10.11_01.pdf (accessed 03/06/2014).

Eurogas (2012) Statistical Report-2012. Eurogas, Brussels, Belgium. See http://www.eurogas.org/uploads/media/ Statistics_2012_21.11.12.pdf (accessed 03/05/2013).

Eurostat (2014a) Import (by Country of Origin)-GasMonthly Data [nrg_124m]. Eurostat, Luxembourg. 
See http://appsso.eurostat.ec.europa.eu/nui /show.do?dataset=nrg_124m\&lang=en (accessed 10/03/2014).

Eurostat (2014b) Supply-Gas-Monthly Data (nrg_103m). Eurostat, Luxembourg. See http://epp.eurostat.ec.europa. eu/portal/page/portal/energy/data/database (accessed $15 / 03 / 2014)$.

FICO (2014) FICO Xpress Optimisation Suite. FICO, San Jose, CA, USA. See http://www.fico.com/en/products/ficoxpressoptimization-suite/ (accessed 02/03/2014).

GLE (Gas LNG Europe) (2014) GLE LNG Map Dataset in Excel-Format. GLE, Brussels, Belgium. See http://www.gie. eu/index.php/maps-data/lng-map (accessed 16/06/2014).

GSE (Gas Storage Europe) (2014) GSE Storage Map Dataset in Excel-Format. GSE, Brussels, Belgium. See http://www. gie.eu/index.php/maps-data/gse-storage-map (accessed 15/06/2014).

Holz F, Von Hirschhausen C and Kemfert C (2008) A strategic model of European gas supply (GASMOD). Energy Economics 30(3): 766-788.

Honore A (2014) The Outlook for Natural Gas Demand in Europe. Oxford Institute for Energy Studies, Oxford, UK. See http://www.oxfordenergy.org/wpcms/wp- content/ uploads/2014/06/N-87.pdf (accessed 15/11/2014).

IEA (International Energy Agency) (2009) Natural Gas Reviews 2009. IEA, Paris, France.

IEA (2011) World Energy Outlook: are we Entering a Golden Age of Gas? IEA, Paris, France.

IEA (2012) Natural Gas Information. IEA, Paris, France. See http://www.iea.org/media/training/presentations/ statisticsmarch/NaturalGasInformation.pdf (accessed 12/11/2014).

Lise W, Hobbs BF and Van Oostvoorn F (2008) Natural gas corridors between the EU and its main suppliers: simulation results with the dynamic GASTALE model. Energy Policy 36(6): 1890-1906.

Lochner S and Bothe D (2007) From Russia with Gas an Analysis of the Nord Stream Pipeline's Impact on the European Gas Transmission System with the TIGER-model. Institute of Energy Economics at the University of Cologne, Cologne, Germany, EWI Working Paper 07/2.

National Grid (2012) Gas Ten Year Statement. National Grid, London, UK. See http://www.nationalgrid.com/NR/ rdonlyres/E60C7955-5495-4A8-8E80-8BB4002F602F/ 58097/GasTenYearStatement2013.pdf (accessed 15/01/ 2013).

Noel P, Findlater S and Chyong CK (2012) The Cost of Improving Gas Supply in the Baltic States. Electricity Research Working Group, University of Cambridge, Cambridge, UK. See http://www.econ.cam.ac.uk/dae/repec/ cam/pdf/cwpe1204.pdf (accessed 30/10/2014).

Pöyry (2010) Security of Gas supply in European Scenarios, Policy Drivers and Impact on GB. Pöyry Energy (Oxford) Ltd, Oxford, UK. See http://www.decc.gov.uk/assets/decc/ What we do/UK energy supply/Energy markets/gas_ markets/115-poyry-europe.pdf (accessed 28/01/2013).

Stern J (2009) The Russo-Ukraine gas Dispute of January 2009: a Comprehensive Assessment. Oxford Institute of Energy Studies, Oxford, UK, NG 27.

Szikszai A and Monforti F (2011) GEMFLOW: a time dependent model to assess responses to natural gas supply crises. Energy Policy 39(9): 5129-5136.

Thompsom M, Davison M and Rasmussen H (2009) Natural gas storage valuation and optimisation: a real options application. Naval Research Logistics 56(3): 1265-1279.

\section{WHAT DO YOU THINK?}

To discuss this paper, please email up to 500 words to the editor at journals@ice.org.uk. Your contribution will be forwarded to the author(s) for a reply and, if considered appropriate by the editorial panel, will be published as discussion in a future issue of the journal.

Proceedings journals rely entirely on contributions sent in by civil engineering professionals, academics and students. Papers should be 2000-5000 words long (briefing papers should be 1000-2000 words long), with adequate illustrations and references. You can submit your paper online via www.icevirtuallibrary.com/content/journals, where you will also find detailed author guidelines. 